Hentschke, Cynthia S., Amorim, Luciana G., Formoso, Carlos T., Tzortzopoulos, Patricia, and Echeveste, Marcia E. S. (2019). "Connections Between Mass Customization Best Practices in Housing and Lean Production." In: Proc. 27th Annual Conference of the International. Group for Lean Construction (IGLC), Pasquire, C. and Hamzeh, F.R. (ed.), Dublin, Ireland, pp. 1369-1380. DOI: https://doi.org/10.24928/2019/0267. Available at: <www.iglc.net>.

\title{
CONNECTIONS BETWEEN MASS CUSTOMISATION PRACTICES IN HOUSING AND LEAN PRODUCTION
}

\author{
Cynthia S. Hentschke ${ }^{1}$, Luciana G. Amorim², Carlos T. Formoso ${ }^{3}$, Patricia \\ Tzortzopoulos $^{4}$ and Marcia E. S. Echeveste ${ }^{5}$
}

\begin{abstract}
The understanding of customers' needs and preferences in housing is complex. In order to respond to this, housing companies should be able to offer a higher product variety while ensuring cost effectiveness. Mass customisation (MC) has been suggested as an effective strategy for balancing the fulfilment of clients' needs and at the same time keep costs and delivery time within acceptable limits. Several MC practices have been associated to Lean Production (LP), such as reducing lead time, increasing value by systematically capturing customer requirements, and increasing output flexibility. The aim of this paper is to identify a set of MC practices in housebuilding, discuss their underlying concepts and principles, exploring their connections to LP. The identification of common concepts and principles between LP and MC can support the definition of the MC strategy for housing companies and also the adaptation of best practices to different organisational contexts. Results are based on a literature review and a case study developed with a Brazilian house-building company. The main contribution is better understanding trade-offs between productivity and flexibility with the aim of improving value generation in housing projects.
\end{abstract}

\section{KEYWORDS}

Lean construction, mass customisation, housing.

Ph.D. Candidate, Building Innovation Research Unit (NORIE), Universidade Federal do Rio Grande do Sul, Porto Alegre, email: cynthiahentschke@gmail.com

2 M.Sc., Postgraduate Building Innovation Research Unit (NORIE), Universidade Federal do Rio Grande do Sul, email: lugheller@gmail.com

3 Professor, Building Innovation Research Unit (NORIE), Universidade Federal do Rio Grande do Sul, email: formoso@ufrgs.br

4 Professor, Associate Dean for research and Enterprise, School of Art, Design and Architecture, University of Huddersfiled, UK, email: p.tzortzopoulos@ hud.ac.uk

5 Professor, Postgraduate Program in Industrial Engineering (PPGEP), Universidade Federal do Rio Grande do Sul, Porto Alegre, email: echeveste@ producao.ufrgs.br 
Hentschke, Cynthia S., Amorim, Luciana G., Formoso, Carlos T., Tzortzopoulos, Patricia, and Echeveste, Marcia E. S.

\section{INTRODUCTION}

Mass Customisation (MC) is an organisational strategy that aims to offer products that fulfill customers' requirements, potentially adding value, through flexible process and structure, with costs and delivery time similar to mass production (Pine, 1993; Hart, 1995; Jiao, Ma, \& Tseng, 2003; Fogliatto, da Silveira, \& Borenstein, 2012). The main challenges in the application of $\mathrm{MC}$ for housebuilding companies to are capturing customers' requirements (Barlow \& Ozaki, 2003; Tillmann and Formoso, 2008; Martinez et al., 2017) and keeping the balance between offering variety and maintaining housing affordability (Martinez et al., 2017) without affecting the efficiency of the production process (Nahmens $\&$ Bindroo, 2011). In the last 20 years, several studies have proposed ways to overcome this challenge in manufacturing. Furthermore, previous research suggest the combination of different practices and strategies to deliver mass custom goods (Ferguson, Olewnik, \& Cormier, 2014; Fettermann, 2013; Piller, Moeslein, \& Stotko, 2004).

Koskela (2000) states that the consolidation of lean production has played a key role in the emergence of MC in the beginning of the 1980s, based in the value generation perspective. Piller, Moeslein, \& Stotko (2004) describe that the use of the concept of value generation in different production systems and strategies, such as agile, lean and MC, have the common goal of increasing cost-effectiveness and ability to react to heterogeneous and constantly changing market demands. Agile and Lean are also considered as enablers to mass customisation (Fogliatto et al., 2012). However, exploring the relationship between agile, lean and mass customisation is a significant research gap yet to be addressed (Fogliatto et al., 2012). Although the combination lean and $\mathrm{MC}$ have been raised in the literature its implications have not been addressed in detail still (Stump \& Badurdeen, 2012). According to Nahmens and Bindroo (2011), in the house building industry the combination of lean and MC are particularly interesting due to the challenges provided by its context of application, and can be regarded as way to achieve and maintain continuous improvement and efficiency in operations and strategic levels. Moreover, there is a lack of discussion on which are the specific relationship between MC and Lean concepts and limited empirical evidence on how those connections can enable MC and ease the implementation of related practices.

The aim of this paper is to identify a set of MC practices in housebuilding, discuss their underlying concepts and principles, exploring connections to Lean Production. The identification of common concepts and principles can support the definition of $\mathrm{MC}$ strategies for housing companies and also the adaptation of good practices to different organisational contexts.

\section{MASS CUSTOMISATION}

The implementation of MC depends on fundamental changes in the product development process, so that the diversity of customer requirements is systematically considered, and opportunities for cost savings created (Ferguson et al., 2014; Fettermann, 2013; Piller et al., 2004). These changes depend on the coordinated efforts of three different areas: Customer Integration, Product Design and Operations (Ferguson et al., 2014; Rocha, 2011; Schoenwitz, Potter, Gosling, \& Naim, 2017). Customer integration is concerned with 
understanding the demand for customisation by capturing customers' requirements and translating them into product specifications, customer-supplier interaction process, tools and the solution space definition (Ferguson et al., 2014; Rocha, 2011). The product design area involves developing design concepts and solutions, including product architectures and product-service systems, based on the customisation units chosen by customers (Ferguson et al., 2014; Rocha, 2011). Operations can be regarded as a way to produce and deliver customized goods by managing production and supply chains to ensure that the costs and time are below a certain limit. Rocha (2011) recommends that the definition of the strategy should begin from the core categories which outline the MC strategy to then proceed to other areas above mentioned.

In house-building, several MC practices and approaches have been presented in the literature (e.g. Rocha, 2011; Schoenwitz et., 2012; Shin et al. 2008; Tillmann and Formoso, 2008; Noguchi \& Hernández-Velasco, 2005; Barlow and Ozaki, 2002; Naim and Barlow, 2002). Fetterman (2013) defines practices as methods, tools, techniques, which can be combined to support the introduction of changes in the product development. When translated into abstract ideas, practices can be transferred from different contexts and cultures to be applied (Lillrank,1995). This practical-theoretical reflection is necessary to transcend the mechanical repetition of the existing (Arís, 1998) enabling improvement through critical thinking and reflection (Franco, 2003 apud Amorim, 2018).

According to Balow (1998), MC can be enabled by agile production systems, which aim to respond to the constantly changing market demands by delivering high-quality products and reducing costs and product development process time. The same author argues that agile systems can be regarded as an extension of the lean production philosophy. Furthermore, Pine II (1994) and Barlow (1998) suggest that there are several connections between MC and Lean Production, such as: (i) just-in-time, which contributes to the reduction of waste and stocks; (ii) pull production, which enables the production of goods pulled by customers' orders; (iii) economic batch, in which each product customisation is done by reducing the setup and change over times, responding rapidly to frequently changing customers desires and expectations. Additionally, in both approaches there is a need to manage the supply chain, and to enhance collaboration between stakeholders in orderv to deliver a product that fulfill the customers requirements (Naim \& Barlow, 2002).

In the housing context, the adoption of lean principles combined with MC strategy has been seen a way to reduce the trade-offs of improving value for customers through variety and increasing productivity through standardization (Nahmens \& Bindroo, 2011). The same authors highlight that even though both $\mathrm{MC}$ and Lean construction seek for production efficiencies, lean is not focus on increasing product variety. However, the perspective of the production as a flow and flexibility of the production system can support the offer of high product variation, which is a key feature of MC (Nahmens \& Bindroo, 2011). Additionally, Martinez, Tommelein and Alvear (2017) state that the combination of lean production system with IT can enable the application of MC in affordable housing by reducing lead time, improving communication and shared information.

The challenges for implementing lean principles in MC contexts can increase according to the degree of customisation and level of customers involvement in manufacturing (Stump \& Badurdeen, 2012) as well as in housing (Nahmens \& Bindroo, 2011). Thus, the 
Hentschke, Cynthia S., Amorim, Luciana G., Formoso, Carlos T., Tzortzopoulos, Patricia, and Echeveste, Marcia E. S.

understanding of the connections between MC practices and Lean principles in this research was perceived as an opportunity to comprehend the underpinning ideas from best practices in order to ease their application in different contexts, and apply it on a specific case study. Additionally, identifying these connections can provide some insights of the potential benefits that the construction companies can achieve by applying practices related to a specific decision category and lean principles.

\section{RESEARCH METHOD}

The methodological approach adopted in this research was Design Science Research, which aims to build innovative solution concepts for classes of real world problem and, at the same time, make scientific contributions to a specific field of knowledge (Kasanen, Lukka, \& Siitonen, 1993; Lukka, 2003). In this research, the practical problem addressed was how construction companies can address the productivity-flexibility trade-off and improve cost-benefits through mass customisation strategies. The main theoretical contributions relate to describing relationships between MC decision categories and Lean concepts and principles.

The research process was divided into three stages: (i) understand the problem and identify MC practices in the literature; (ii) assess practices used in an empirical study; (iii) reflect about underlying ideas, analysing the connections between MC and Lean.

A set of practices was identified in a literature review focused on mass customisation in the construction industry. The practices were extracted from academic publications, and further categorized according to core functional areas in the companies, their country of application, authorship, etc. Based on the classification of practices, MC decision categories were identified.

In the second phase, an empirical study was undertaken about a house building company from the South of Brazil (Company A). This company has over 20 years of experience, mostly in the upper middle and in the middle-class segments. The provision of customized housing projects as part of the competitive advantage of the company was one of the key elements for its selection for this empirical study. The company has a business unit dedicated to the customisation of housing units, that addresses a set of market segments with different levels of choice. This study addresses a relatively new product line in which the company provides a limited offering to fulfill customer's choices. Focusing on the line that fits the most the MC approach, where the productivity-flexibility trade-off must be managed closely, in order to improve the value generation to customers without substantially increasing costs and lead time.

The third stage of the study involved analysis and reflection of the empirical study and literature review findings.

Multiple sources of evidence used: (i) 11 semi-structured interviews with architects, managers and other professionals from company A; (ii) 4 open-ended interviews with professionals involved in the customisation process; (iii) analysis of documents related to the customisation process, mostly related to the solution spaces adopted in different projects; (iv) participant observation in planning and control meetings, and in one 
customisation event promoted by the company; and (v) 3 meetings to discuss the customisation process map and improvement opportunities.

\section{RESULTS}

\section{IDENTIFICATION OF BEST PRACTICES IN THE LITERATURE}

Based on the literature review approximately $100 \mathrm{MC}$ practices in housing were identified in different countries, e.g. Japan, United Kingdom, Germany, Brazil, Ecuador, Mexico and South Korea. Practices were classified into several decision categories, which were divided into four groups: core categories, product design, customer integration and operations. The main decision categories are presented below, some of which were proposed by Rocha (2011), and others emerged as part of the literature review carried out in this investigation.

The core categories are related to the establishment of the MC strategy and definition of product variety, are they: (i) Solution Space (adapted from Rocha (2011)), (ii) Strategy and customisation level (adapted from Rocha (2011)), (iii) Assessment and feedback and (iv) communication of the information about customization. The solution space is a set of customisation units (i.e. the customizable attributes of the product and their range of options) and rules for combining them to be offered to customers, which outlines the definition of product variants in a MC strategy (Rocha, 2011; Salvador; Holan; Piller, 2009). When proposed by Rocha (2011) the solution space and customization units were two different decision categories. However, a fusion of this decision categories is proposed due to their interdependency, once there is no solution space without customization units and the customization units need to be combined in solutions space in order to be offered to customers. The second decision category is related to the MC Strategy and level of customization, the level or taxonomies of customisation refer to the strategy that companies adopt to satisfy different markets through the value chain (Fogliatto; Da Silveira; Borenstein, 2012). It is related to the customer order decoupling point (CODP) and product variants definitions, providing a holistic view of the process. Additionally, this category relates to the company's competitive strategy and position in the market. The second adaptation proposed is the consideration of the level of customization to be a core concern for the establishment of the customization strategy, rather than what was proposed by Rocha (2011) to be only related to production.

The new core categories defined based on the literature review and researchers insights from the empirical study are (iii) Assessment and feedback and (iv) Communication of customisation information. The third core decision category mentioned addresses the need for defining the approaches to assess customers demand for customisation to establish a solution space accordingly and to evaluate the delivered product after occupancy to understand emerging and evolving requirements. Additionally, it is necessary to establish how is this information will be used to feedback the PDP. It is strongly related to Customer integration and value generation. The fourth core decision category is related to one of the key issues in companies that implement MC that is the improvement of the information flow between departments to facilitate collaboration and increase value generation (Barlow, 1998; Martinez et al., 2017; Tillmann \& Formoso, 2008). This decision category embraces practices that promote transparency and continuous improvement, by making relevant 
Hentschke, Cynthia S., Amorim, Luciana G., Formoso, Carlos T., Tzortzopoulos, Patricia, and Echeveste, Marcia E. S.

customisation information available to stakeholders along the product development process.

Customer integration related practices are: (i) Visualization Approaches (Rocha (2011)) (ii) Configuration Sequence (Rocha (2011)) (iii) Customer interaction and relationship. The visualization approaches are related to the Definition of how and to whom (i.e. customer, company or both) customisation units will be displayed (Rocha, 2011). There are three types of approaches: collaborative, transparent and Do-It-Yourself (Rocha, 2011). This category of decision is also related to the existing interface with clients and provided information about the process for customers. The second decision category related to the customer integration practices is the configuration sequence, which involves the establishment of the sequence of customisation units or decisions to be made by customers in the product configuration process in order to define variants (Rocha, 2011). The sequence is deeply influenced by the level of customisation and customisation units available. The third decision category mentioned in this group, was proposed in this research, and is related to the definition of the approaches to interact with clients along the product configuration process and the development of a relationship with customers to achieve loyalty.

The decision categories related to operations and supply chain proposed by Amorim (2018), strongly related to different lean principles, are: (i) Supply Chain Management, (ii) Production Planning and Control Emphasizing Pull Production, and (iii) Production System Flexibility. The supply chain management decision category is related to increasing the output flexibility and transparency, simplify by reducing the number of parts, reduce the batch size and lead time, and improve value generation (Koskela, 2000). The second decision category in this group is concerned with controlling production and managing information flows according to the release of customer order. The company must align the production planning and control system with the customisation offered to customers to be able to deliver customised housing units. According to Koskela (2000), pull production can bring benefits such as increasing the output flexibility and transparency, and reduce the lead time.

\section{ANALYSIS OF THE CUSTOMISATION STRATEGY OF COMPANY A}

Company A's Customisation Department is responsible for the definition of the solution space for each project. At the conceptual stage, customisation units (i.e.: customizable attributes and their available options) of the housing unit layout and finishings to be offered to customers are discussed with the Product Development Department. Subsequently, the layout customisations units and deadline for customisation decisions are defined by the Project Launch Committee. An event involving several departments of the company is carried out for each new conceptual design a brief that is delivered to architecture designers.

After the project launches into the market, clients will choose a layout option when buying the units. The customisation department is responsible for processing that information and delivering it to the construction site. Simultaneously to sales, customisation units related to the finishings are defined by the customisation team. These customisation units are later offered to clients in an event, named "first visit", in which clients visit a housing unit prototype. During the event, a customisation guide is delivered 
to customers so that they can choose alternatives from a kind of choice menu. Afterwards, customers have to sign an additional contract concerned with the customisation of housing units and this information is processed and summarized to be delivered to the production management team. Finally, the customisation team performs periodic construction site visits to check the fulfillment of the customer order.

\section{Assessment of the practices in company A}

From the set of practices identified in the literature, only 75 were assessed in this empirical study, excluding the 25 design related practice, since the design of the projects for company A was done by subcontracted architectural and engineering firms. An assessment was made on the degree of implementation of practices, according to a 5 points scale: applied, partially applied, not applied, improvement recommended, recommended. Error! Reference source not found. presents an overview of the degree of implementation of practices according to decision categories. This assessment was based in the multiple the sources of evidence of the study, especially in the semi-structured interviews and the analysis of documents.

The customer interaction and relationship category had the highest degree of implementation, mainly due to the creation of several communication channels with customers, which allows a follow up to be carried out until project delivery. Additionally, company A applies 2 practices from the set available for communication of customisation information: (i) produce a list of the necessary materials and labour costs for product change to customers and cost estimators; and (ii) visits to the construction site by the customisation team to check the compliance of the product with customisation orders.

Moreover, there were some practices related to visualization approaches to inform customers about the available customisation units and the standard product specifications by interacting with a product prototype. The practice applied regarding production planning and control emphasizing pull production was the use of postponement strategies, through additional work on the delivery. This is done by the offer of additional customisation units to customers related to finishing and furniture among others, after the housing unit is handover, operationalized by the customisation department by coordinating different suppliers.

Many improvement opportunities exist in Company A in the implementation of MC practices: in eighth of the nine decision categories analysed, the full or partial adoption of practices was higher than $50 \%$. Several best practices related to the "information flow along the customisation process" decision category were found in the literature. However, most of them are not found in the Company A. This low rate of application reflects the lack of integration among departments involved in the customisation process, as revealed during the semi-structured interviews. The decision category "assessment and feedback" is another example of improvement opportunity for Company A. Although several best practices were found in the literature, the degree of implementation in that company was very low. In fact, the solution space for each market segment was usually proposed relying in the customisation team expertise only.

Furthermore, the improvement recommended (rose) and recommended practices (red) (Error! Reference source not found.) were proposed according on the identified 
Hentschke, Cynthia S., Amorim, Luciana G., Formoso, Carlos T., Tzortzopoulos, Patricia, and Echeveste, Marcia E. S.

opportunities found in Company A. The most critical decision categories to be addressed were assessment and feedback, communication of customisation information, solution space and production planning and control emphasizing pull production. In those categories, there were practices that could be used in the specific context of Company A.

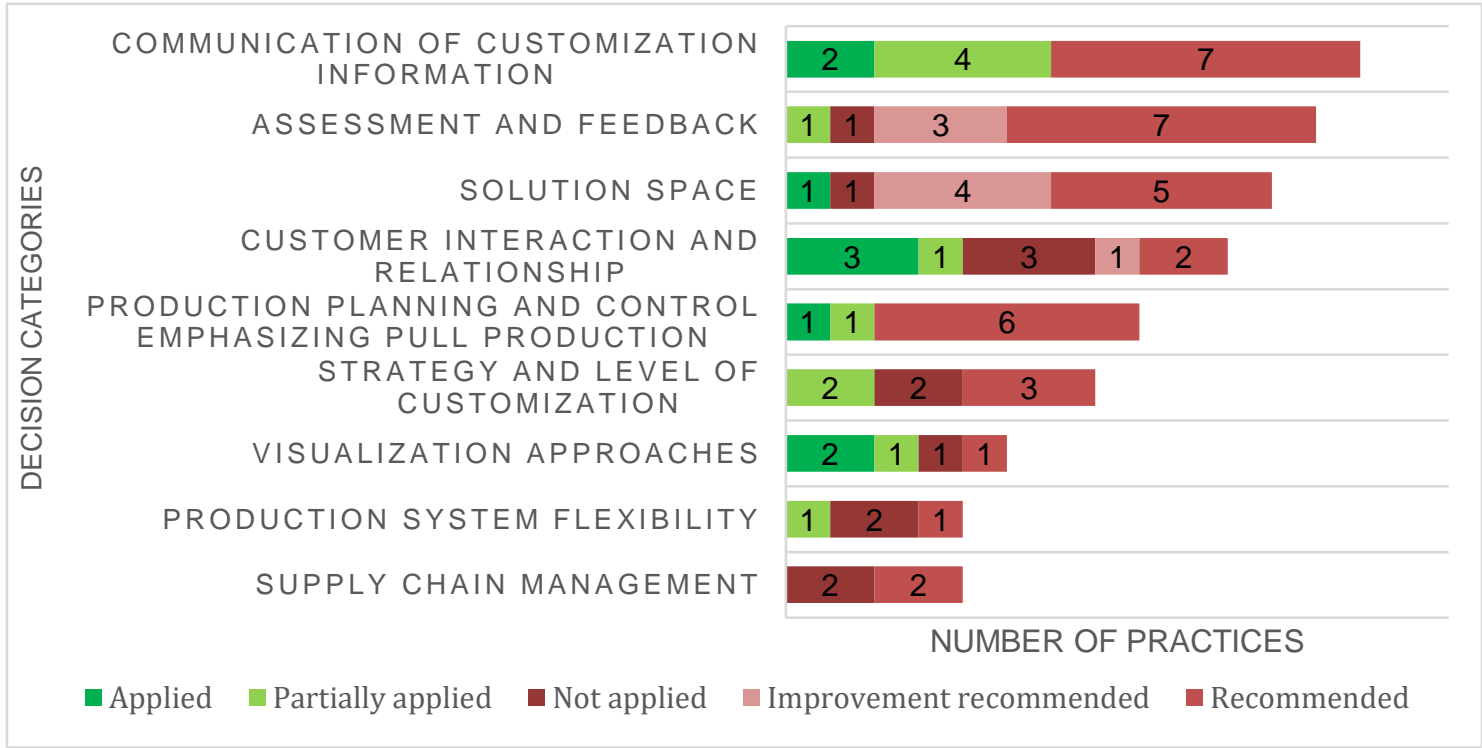

Figure 1: Degree of implementation of practices according to decision categories

Examples of practices and improvements recommended for Company A are briefly described in Table 1. For instance, one key issue identified during the empirical study was that many customers would only be aware that they could customize their housing unit during the "first visit" event. Thus, one of the recommendations made to the company was to inform their clients in product leaflets about how the customisation process occurs and the available solution space to the project. This recommendation can increase the impact of the customisation strategy of the company in attracting potential customers. Another measure that can contribute to the dissemination of the customisation strategy is the development of an informative and advertising area about customisation on the company website.

Table 1: summary of improvement opportunities and recommended practices

\section{Improvement Opportunities $\quad$ Examples of Recommended practices}

Map Customisation process for low- Systematically map the product development process aiming to end projects find process improvement opportunities.

Add a description of customisation process and solution space to product catalogue
Use of catalogues as tool to advertise and inform customers about customisation.
Align the solution space definition with customers' demands
Identify the demand for customisation to define the customisation units and delimitate the solution space. 


\begin{tabular}{cc}
\hline & $\begin{array}{c}\text { Definition of a limited solution space to offer to the clients and } \\
\text { to achieve scale economies. }\end{array}$ \\
$\begin{array}{c}\text { Increase collaboration between } \\
\text { departments and involvement in the } \\
\text { definition of the solution space }\end{array}$ & $\begin{array}{r}\text { The definition of customisation units should balance customers' } \\
\text { perceived value with their production costs. }\end{array}$ \\
\cline { 2 - 2 } $\begin{array}{c}\text { Improve Market research and Post } \\
\text { occupancy assessment methods }\end{array}$ & $\begin{array}{c}\text { Monitor the product in use to capture requirements and feedback } \\
\text { the product development process. }\end{array}$ \\
\hline $\begin{array}{c}\text { Increase the communication between } \\
\text { sectors involved in customisation }\end{array}$ & $\begin{array}{c}\text { Devise a communication channel to collect and share data about } \\
\text { customers' configuration order, monitor its evolution and ease } \\
\text { communication within departments }\end{array}$ \\
\hline
\end{tabular}

\section{DISCUSSION}

According to the literature review, MC and Lean Production share a common ground in many aspects. Indeed, during the process of obtaining an in-depth understanding of the MC practices and decision categories, several connections to Lean concepts and principles emerged, such as the strong relationship between the solution space definition and the value generation concept and the use of pull production to reduce productivity-flexibility tradeoffs. In Figure 2 the a set of relationships between MC practices and Lean Production concepts are summarized, according to decision categories. It is noteworthy that the core decision categories for defining the MC strategy are the ones which present the largest number of connections to Lean concepts: communication of customisation information (7), solution space (7), and strategy and level of customisation (6).

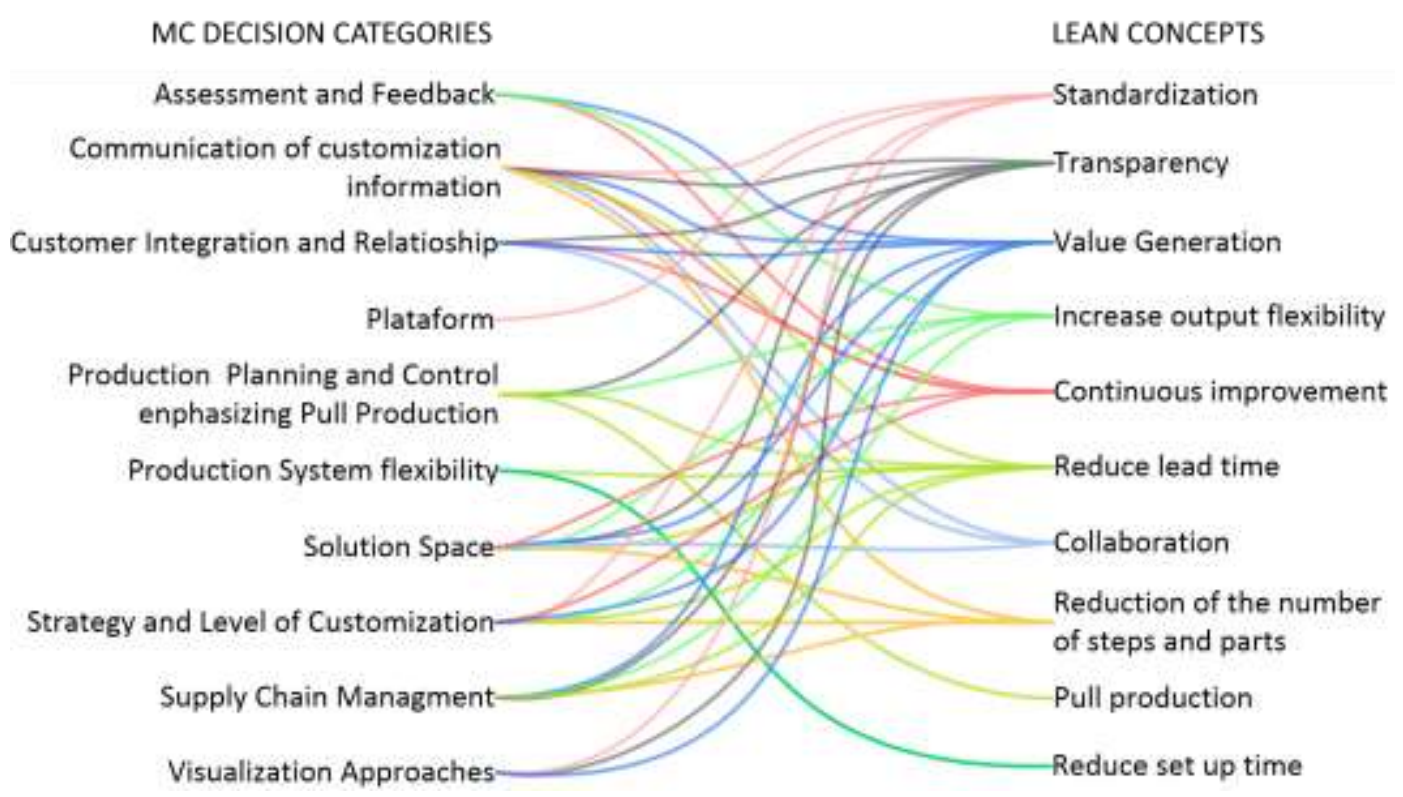

Figure 2: Mass customisation decision categories and Lean Concepts Sankey diagram 
Hentschke, Cynthia S., Amorim, Luciana G., Formoso, Carlos T., Tzortzopoulos, Patricia, and Echeveste, Marcia E. S.

For example, the communication of customisation information is related to standardization of information flows, increasing transparency by showing clearly the customers' orders along product development, and ensuring that customers' requirements are achieved along this process improving value generation. Additionally, it relates to collaboration among the different departments of the company to create trustworthy shared information, contributing also to reduce the lead time, continuous improvement, and reduction of the number of steps and parts. Other decision categories shown more specific connections to Lean concepts, such as the use of pull production, is only related to the production planning and control decision category, while production system flexibility is only related to the reduction of the lead and setup time.

Finally, it is interesting to note that the value generation concept is the one with the largest number of connections to different decision categories, which is coherent with Koslela (2000)'s statement that the emergence of MC is based on this concept. Another noteworthy fact, is that the practices and decision categories related to operations and focusing on the efficiency were easier to connect with the lean principles, corroborating Nahmens and Bindroo 2011 and Stump \& Badurdeen, 2012 findings.

\section{CONCLUSION}

This paper has discussed a set of decision categories for the implementation of MC in house building, and has explored the underlying ideas extracted from MC best practices from different countries that have been reported in the literature. This set of decision categories have been built on previous work (Rocha, 2011), being especially extended in the customer integration and operations groups. In this research some new decision categories were proposed, such as "communication of the customisation information" and "assessment and feedback". In addition, this paper made contributions towards establishing relationships between the decision categories and practices.

From a practical perspective, this set of decision categories were useful for assessing the MC strategy adopted by a house building company from Brazil, and identify some improvement opportunities. From a theoretical perspective, several connections were established between decision categories and Lean Production concepts, which can be helpful for adapting some of the practices to different contexts.

Although this paper explored some relationships between $\mathrm{MC}$ decision categories and lean concepts and principles, there are several opportunities for further development of research studies on the scope of decisions and best practices adopted by house-building companies. Another relevant future research area is the use IT and BIM based tools to support customers' requirement management, visualization approaches, and collaborative processes related to $\mathrm{MC}$, in order to improve decision making and make information flows more effective along the product development process.

\section{ACKNOWLEDGMENTS}

The authors thank the collaboration of Company A, it was key to the development of the research. Also, they thank CAPES for partially sponsoring this study. 


\section{REFERENCES}

Amorim, L. G. (2018) Análise de práticas relacionadas à gestão da produção para apoiar a customização em massa em empreendimentos habitacionais. Ms.C. Diss. Civil Engineering. Universidade Federal do Rio Grande do Sul

Barlow, J. (1998). From craft production to mass customisation? Customer-focused approaches to housebuilding. Proceedings IGLC 98.

Barlow, J., \& Ozaki, R. (2003). Achieving 'customer focus' in private housebuilding: Current practice and lessons from other industries. Housing Studies, 18(1), 87-101. https://doi.org/10.1080/0267303032000076858

Ferguson, S. M., Olewnik, A. T., Cormier, P. (2014). A review of mass customisation across marketing, engineering and distribution domains toward development of a process framework. Research in Engineering Design, 25(1), 11-30. https://doi.org/10.1007/s00163-013-0162-4

Fettermann, D. de C. (2013). Desenvolvimento de produto orientado à customização em massa.

Fogliatto, F. S., da Silveira, G. J. C., Borenstein, D. (2012). The mass customisation decade: An updated review of the literature. International Journal of Production Economics, 138(1), 14-25. https://doi.org/10.1016/j.ijpe.2012.03.002

Formoso, C., Leite, F., \& Miron, L. (2011). Client requirements management in social housing: A case study on the residential leasing program in brazil. Journal of Construction in Developing Countries, 16(2), 47-67.

Hentschke, C. dos S. (2014). Método para identificar atributos customizáveis na habitação baseado no modelo conceitual Cadeia Meios-Fim, 1-181.

Jiao, J., Ma, Q., \& Tseng, M. M. (2003). Towards high value-added products and services: mass customisation and beyond. Technovation, 23(10), 809-821. https://doi.org/10.1016/S0166-4972(02)00023-8

Kasanen, E., Lukka, K., \& Siitonen, A. (1993). The Constructive Approach in Management Accounting Research. Journal of Management Accounting Research, 5(June 1991), 243-264.

Koskela, L. (2000). An exploration towards a production theory and its application to construction. VTT Building Technology.

Lukka, K. (2003). The constructive research aproach. In Ojala, L. \& Himola, O-P.(eds) Case study research in logistics (pp. 83-101). Turku School of Economics and Business Administration, Series B1.

Martinez, E., Tommelein, I. D., \& Alvear, A. (2017). Integration of Lean and information technology to enable a customisation strategy in affordable housing, II(July), 95-102. https://doi.org/10.24928/2017/0136

Nahmens, I., \& Bindroo, V. (2011). Is Customisation Fruitful in Industrialized Homebuilding Industry? Journal of Construction Engineering and Management, 137(12), 1027-1035. https://doi.org/10.1061/(ASCE)CO.1943-7862.0000396

Naim, M., \& Barlow, J. (2002). An innovative supply chain strategy for customized housing. Construction Management and Economics, 21(6), 593-602. https://doi.org/10.1080/0144619032000134129 
Hentschke, Cynthia S., Amorim, Luciana G., Formoso, Carlos T., Tzortzopoulos, Patricia, and Echeveste, Marcia E. S.

Noguchi, M., \& Hernández-Velasco, C. R. (2005). A 'mass custom design' approach to upgrading conventional housing development in Mexico. Habitat International, 29(2), 325-336. https://doi.org/10.1016/j.habitatint.2003.11.005

Piller, F. T., Moeslein, K., \& Stotko, C. M. (2004). Does mass customisation pay? An economic approach to evaluate customer integration. Production Planning \& Control, 15(4), 435-444. https://doi.org/10.1080/0953728042000238773

Pine II, B. J. (1994). Personalizando produtos e serviços : customização maciça. Makon Books do Brasil, São Paulo.

Rocha, C. G. da. (2011). A conceptual framework for defining customisation strategies in the house- building sector.

Schoenwitz, M., Naim, M., \& Potter, A. (2012). The nature of choice in mass customized house building. Construction Management and Economics, 30(April), 203-219.

Schoenwitz, M., Potter, A., Gosling, J., \& Naim, M. (2017). Product, process and customer preference alignment in prefabricated house building. International Journal of Production Economics, 183(September 2015), 79-90. https://doi.org/10.1016/j.ijpe.2016.10.015

Shin, Y., An, S.-H., Cho, H.-H., Kim, G.-H., \& Kang, K.-I. (2008). Application of information technology for mass customisation in the housing construction industry in Korea. Automation in Construction, 17(7), 831-838. https://doi.org/10.1016/j.autcon.2008.02.010

Stump, B., \& Badurdeen, F. (2012). Integrating lean and other strategies for mass customization manufacturing: A case study. Journal of Intelligent Manufacturing, 23(1), 109-124. https://doi.org/10.1007/s10845-009-0289-3

Tillmann, P. A., \& Formoso, C. T. (2008). Opportunities to adopt mass customisation - a case study in the brazilian house building sector. Proceedings for the 16 Annual Conference of the International Group for Lean Construction, 447-458. 